\title{
La construcción del lector en la narrativa policial de Borges. Teoría y práctica de ¿un género menor?
}

\author{
Alejandra G. Amatto Cuña*
}

Resumen:

Los cuentos policiacos de Borges contribuyeron a que la recepción de este tipo de textos evolucionara, debido a que el argentino también reflexionó en sus ensayos acerca de las características de una narrativa en ocasiones menospreciada. Por el contrario, el autor de "La muerte y la brújula" estudió el tipo de lector que lo policiaco construye, lo cual lo llevó a reivindicar un relato que, desde su postura, contribuyó al enriquecimiento del panorama literario de su época. Borges además hizo hincapié en el rigor del cuento policial, el cual contrastó con otro tipo de literatura, en la cual imperaba lo que para él era "caótico", como la supresión de personajes y argumentos. Sin embargo, Borges llevará a cabo una subversión del género que puede constatarse en el cuento antes mencionado, por ejemplo, en el cual las funciones tradicionales del policía y el criminal son puestas en entredicho, desde el momento en que estos no cumplen con determinados aspectos de la tradición (que el cuentista ya había analizado en sus disquisiciones ensayísticas en torno a Poe, Chesterton y Arthur Conan Doyle). El resultado es una nueva lectura de los modelos clásicos y la problematización de los caracteres que se ponen en juego en lo policial.

${ }^{*}$ El Colegio de México. 
Palabras clave:

Policiaco, tradición, literatura argentina, recepción.

Si los caracteres de una ficción pueden ser lectores o espectadores, nosotros sus lectores o espectadores, podemos ser ficticios. JLB, Otras inquisiciones

Entre 1930 y 1940, Jorge Luis Borges publica en revistas como El Hogar y Sur la mayoría de las reseñas, prólogos y artículos que dedica al estudio de la literatura policial. En estos ejercicios metódicos, cuya recepción inicial podría haberlos remitido solo a algunos comentarios acerca de las características más importantes del género, se encuentra una propuesta teórica destacada que resume y contribuye a difundir los aspectos esenciales de este tipo de narrativa. Fue mediante esta labor crítica e interpretativa que Borges delimitó lo que consideraba las directrices más importantes del género policial y estableció, como señala Martha Castellino, su canon personal. Antes de esta década, existen solo algunos antecedentes acerca del interés que esta literatura suscitaba en el autor argentino como "un relato publicado en 1927 en Martín Fierro, llamado 'Leyenda policial' y luego incluido en El idioma de los argentinos (1928) bajo el título de "Hombres pelearon"' (Castellino 89-90).

Sin duda alguna los postulados más destacados del género, e incluso su delimitación - un debate nada sencillo al que me referiré más adelante-, se producen fundamentalmente por la capacidad del escritor de dar con las claves más elementales y necesarias para comprender y posicionar a la literatura policial como formadora de un tipo de lector específico que el propio género, bajo una serie de procedimientos y transformaciones paulatinas, irá construyendo. Este lector, necesariamente, debe apelar a la inteligencia y al agudo razonamiento para poder resolver el enigma que todo texto policial presenta. No es casual que en este mismo periodo se hayan escrito los dieciséis cuentos que conforman Ficciones (1944) y, entre ellos, "La muerte y la brújula", que según el mismo Borges sería un intento del género policial del que no 
estaba demasiado orgulloso, pues lo había llevado a un terreno simbólico que tal vez no era el más apropiado. ${ }^{1}$

Sin el afán de contradecir al autor, el cuento "La muerte y la brújula", además de establecerse como un texto esencial dentro de la literatura policiaca hispanoamericana, constituye con los artículos y reseñas que lo anteceden, un corpus referencial que será decisivo dentro de la evolución del género. De la integración de este corpus se desprenden dos aspectos que serán el objeto de análisis en este trabajo.

El primero de ellos se relaciona con el papel que jugó este cuento y los textos críticos en la trasformación de la percepción literaria de la época acerca de la narrativa policial. El autor argentino no solo desarrolló una teoría del policial en sus reseñas y artículos sino que llevó esa teoría a la práctica, la transformó e incluso la superó en varios de sus cuentos: uno de los más significativos es, en este sentido, el protagonizado por Lönnrot.

El segundo aspecto que me interesa analizar es la percepción acertada de Borges acerca del tipo de lector que la narrativa policial crea y, en más de un sentido, construye. Para esto es imprescindible comprender su propuesta teórica, ya que la idea de un lector específico proviene del profundo conocimiento que este autor tenía del género. Asimismo, será necesario contemplar las demandas del lector tradicional, que obliga al escritor del policial a remitirse a un modelo esquemático y restringido para colmar sus expectativas.

Los aportes de Borges a la teoría del género policial, junto con la subversión de algunas de sus leyes y de diversos elementos clásicos en sus cuentos, demuestran que esta narrativa era una de las pasiones del autor en el periodo. De ahí su defensa y preocupación por explicar al policial como un género claramente constituido que, a pesar de sus muchos detractores, contribuía al enriquecimiento del panorama literario de la época.

\footnotetext{
1 "He intentado el género policial alguna vez, no estoy demasiado orgulloso de lo que he hecho. Lo he llevado a un terreno simbólico que no sé si cuadra. He escrito 'La muerte y la brújula"” (Borges, "El cuento" 197).
} 
$\mathrm{Al}$ realizar una lectura detenida de las numerosas reseñas que Borges publica en las revistas del período destaca un hecho importante: la empecinada pero siempre sutil tarea de definir al género policial como uno de los más exquisitos en la literatura y no como uno menor. Si se observa esta polémica desde una perspectiva actual en la que "las distinciones genéricas han perdido interés, y los géneros sólo parecen haber sobrevivido para ser objetos del uso distante, la trasgresión o la mezcla" (Pastormerlo 17), la pugna por el posicionamiento del policial parecería ser estéril. Pero no deja de ser significativo que autores como Todorov extraigan de esta narrativa una rica fuente para establecer clasificaciones que no solo se aplican al género sino a toda la literatura. Así, el crítico distingue dos campos literarios de acción que se diferencian por la relación entre obra y género. Uno, el de la "gran literatura", que comprende la ruptura y la heterogeneidad. El otro, denominado "literatura de masas", está compuesto por la uniformidad y la obediencia a las normas del género.

En cuanto a la primera clasificación, el estudioso sostiene que “tout grand livre établit l'existence de deux genres, la réalité de deux normes: celle du genre qu'il transgresse, qui dominait la littérature précédente; et celle du genre qu'il crée" (56). Si para el crítico, todo gran libro establece la existencia de dos géneros, la realidad de dos normas: la del género que transgrede, que dominaba la literatura precedente, y la del género que crea, de sus reflexiones se desprende una premisa importante: una obra literaria de cualidades excepcionales puede romper con la tradición a la que pertenece y fundar una nueva. Claro está, sin prescindir nunca de su antecedente, porque para modificarlo será necesaria la referencialidad que este impone.

En la segunda categoría de su artículo, Todorov sitúa a la novela policial, pues afirma que esta tiene normas propias: "Le roman policier a ses normes; faire 'mieux' qu'elles ne le demandent, c'est en même temps faire moins bien: qui veut 'embellir' le roman policier, fait de la 'littérature', non du roman policier. Le roman policier par excellence n'est pas celui qui transgresse les règles du genre, mais celui qui s'y conforme" (56). Aquí se presentan algunas elaboraciones fundamentales. Quien quiere "embellecer" a la novela 
policial hace "literatura", no novela policial. La novela policial por excelencia no es la que transgrede las reglas del género, sino la que se conforma a ellas. En este sentido, la literatura policial parecería no pertenecer al grupo que encabeza las rupturas dentro de los géneros. Como consecuencia de esta afirmación, viene una segunda premisa: las reglas del policial son fijas y en esta condición recae toda su esencia.

Algunos años antes, Borges ya había reflexionado acerca de las características que constituyen la esencia del género, y en su condición de "teórico no confeso" del policial, sostiene lo siguiente:

¿Qué podríamos decir como apología del género policial? Hay una que es muy evidente y cierta: nuestra literatura tiende a lo caótico. Se tiende al verso libre porque es más fácil que el verso regular; la verdad es que es muy difícil. Se tiende a suprimir personajes, los argumentos, todo es muy vago. En esta época nuestra, tan caótica, hay algo que, humildemente, ha mantenido las virtudes clásicas: el cuento policial ("El cuento" 197). ${ }^{2}$

Tanto Borges como Todorov coinciden en que el policial requiere de la estabilidad y del orden para mantener su condición de género. Pero existen dos elementos que me parece necesario distinguir entre sus afirmaciones. El primero es que mientras el crítico de origen búlgaro se refiere fundamentalmente a la novela, Borges se centra en el relato breve y, específicamente, en el cuento. Este no es un asunto superficial, ya que para el escritor "el género policial se presta menos a la novela que al cuento" ("Wilkie" 49). La novela policial, al tener características centrales inamovibles y necesarias por definición, está sujeta a ellas y corre muchas veces el riesgo de automatizarse. En cambio, el cuento policial por su extensión y características no parece tener que estar sometido a todas las reglas que rigen a la novela. Una prueba clara de ello son los textos policiales que Borges publica en Ficciones, un libro en el que los

\footnotetext{
${ }^{2}$ Las cursivas son mías.
} 
cuentos responden a "irrealidades visibles del arte, reflexiones estéticas, [que] serán el punto de llegada. Allí se resuelve (se disuelve) la contradicción. Por eso el principio estético de Ficciones es buscar irrealidades que confirmen el carácter alucinatorio del mundo" (Ramos 164). Características que, evidentemente, desde la perspectiva de Todorov no regirían los textos policiales.

El otro aspecto que me parece importante señalar y que está íntimamente relacionado con el anterior es la postura totalizadora que en cuanto a género asume Todorov. Para ello me baso en la propia obra de Borges. El escritor observa que "los géneros literarios dependen, quizá, menos de los textos que del modo en que éstos son leídos. El hecho estético requiere la conjunción del lector y del texto y sólo entonces existe" ("El cuento" 189). Cuando Todorov postula su idea de ruptura genérica no toma en cuenta el papel fundamental del lector quien es, finalmente, el que procesará el grado de la ruptura.

Contraponiéndose con esta propuesta de funcionamiento de la narrativa policial, en la que se apoyan algunas concepciones que solo reconocen el género a través de manifestaciones convertidas en estereotipo, existe:

otra tradición del policial que se escribe bajo el régimen de las literaturas de "autor". Todos los rasgos antes mencionados que definen la producción de una literatura de masas aparecen, en esta zona del policial, invertidos: esta literatura policial se aparta del estereotipo, porque en este espacio la norma consiste en transgredir o usar libremente los géneros, su público es más reducido y homogéneo (Pastormerlo 19).

A este grupo, sin duda alguna, pertenecen los textos policiales de Borges. Pero ¿cómo lograr subvertir un género? Es decir, ¿cómo incluir parte del mismo como componente en una síntesis o clasificación más abarcadora o considerarlo como parte de un conjunto más amplio o como caso particular sometido a un principio o norma general? Las ficciones y ensayos de Borges muestran cómo "los procedimientos formales del policial son eficaces para la pre- 
sentación de cualquier idea o problema, aun de aquellos que, por su tema, no guardan afinidad con el género" (Parodi 80). Borges obtuvo la solución al problema de la "ruptura" o "subversión" del mismo, sistematizando primero que nada las características esenciales del genuino relato policial. Para el escritor argentino esta narrativa "rehúsa con parejo desdén los riesgos físicos y la justicia distributiva... Las cotidianas vías de la investigación policial -los rastros digitales, la tortura y la delación- parecerían solecismos ahî" ("Los laberintos" 96).

Borges prefiere el relato policial breve por encima de la novela. Sostiene que el primero es de "carácter problemático" y estricto, mientras que el segundo, "linda con la novela de caracteres o psicológica", similitud que parecería no agradarle. Para el escritor, el código del cuento policial clásico se resume en seis puntos: 1) un límite discrecional de seis personajes, 2) declaración de todos los términos del problema, 3) avara economía en los medios, 4) primacía del cómo sobre el quién, 5) el pudor de la muerte, 6) necesidad y maravilla en la solución ("Los laberintos" 96-97). El primer punto es la causa fundamental que según Borges propicia el hastío y la confusión de todos los films policiales. La excesiva cantidad de sujetos colocados en una misma historia provoca que ninguno de ellos logre atrapar la atención del lector y solo consigue que este confunda sus acciones con las de los demás personajes.

Para el autor, el famoso escritor de las sagas de Sherlock Holmes, Conan Doyle, es quien más incurre en la segunda falta, pues apela a estrategias de escamoteo de información graves que van en detrimento del lector como "leves rastros de ceniza" recogidos a espaldas de este, y provenientes de un único y exclusivo lugar que solo el detective conoce. O peor aún, un culpable desconocido, "terriblemente desenmascarado a última hora", una de las maniobras más innobles que puede cometer un autor del género. En los buenos cuentos policiales: "el criminal es una de las personas que figura desde el principio" ("Los laberintos" 97).

En lo que se refiere a la avara economía de los medios, Borges sostiene que este procedimiento de duplicidad de un mismo personaje solo será válido si no se recurre a soluciones simples como una bar- 
ba postiza o una voz extranjera impostada. El recurso debe basarse en "distintas circunstancias y nombres". La primacía del cómo sobre el quién, es otro de los principios que más seducen al escritor y se relaciona con el carácter razonador de los personajes. Asimismo, el pudor de la muerte es uno de los principios que caracterizan a la literatura policial inglesa, referente esencial del género.

El último principio, necesidad y maravilla en la solución, delimita la realidad del problema, y su disposición para una sola solución, que deberá maravillar al lector sin apelar nunca a explicaciones esotéricas o fantásticas. Una de las mayores virtudes del relato policial es:

la presentación y refutación de hipótesis falsas. Es en esta sucesión de hipótesis donde el cuento policial se confunde con el fantástico porque hasta que no llega la explicación última, que suele ser racional y cotidiana, las hipótesis intermedias sugieren hipótesis terribles, fantásticas o sobrenaturales. Este es, precisamente, el esquema de todos los relatos de Chesterton (Castany 9).

Borges plantea que el escritor inglés logra conjuntar los dos géneros -el fantástico y el policial- que Poe siempre mantuvo separados. En cada una de las historias de la saga del padre Brown, Chesterton "presenta un misterio, propone explicaciones de tipo demoníaco o mágico y las reemplaza, al fin, con otras que son de este mundo" ("Chesterton" 72). Esta es una de las características que más admira y distingue de su prosa.

El policial tendrá como premisa un crimen que plantea un enigma que apela al razonamiento lógico para su resolución y no a mecanismos cientificistas simples. Para Borges el gran novelista del policial "suele proponer una aclaración vulgar del misterio y deslumbrar a sus lectores con una solución ingeniosa" (Half-Way 217). Esta debe ser inesperada, nunca sobrenatural o fantástica. Con esto, se obtiene "otra tradición del cuento policial: el hecho de un misterio descubierto por obra de la inteligencia, por una operación intelectual" ("El cuento" 193). 
Pero ¿dónde se inicia esta tradición del policial de enigma que tanto seduce a Borges? Para el escritor existe un precursor excepcional del género y un cuento fundacional del mismo: Edgar Allan Poe y "Los crímenes de la calle Morgue". En su análisis sobre la importancia que el autor estadounidense tuvo para la narrativa policial, Borges sostiene que Poe no quería que este fuera un género realista, "quería que fuera un género intelectual, un género fantástico..., pero un género fantástico de la inteligencia, no de la imaginación solamente; de ambas cosas desde luego, pero sobre todo de la inteligencia" ("El cuento" 193). Estas afirmaciones son muy significativas, ya que a pesar de colocar en la figura de un norteamericano la invención del género, Borges se inclinará siempre por la tradición inglesa, en particular la de Chesterton, rechazando los rumbos posteriores que la literatura policial tomó en Estados Unidos hacia la novela negra.

El gran aporte de Poe al relato policial fue su contribución para la conformación de este como género intelectual, basado en lo ficticio. En uno de sus cuentos modelo, "La carta robada", el crimen se descubre "por un razonador abstracto y no por delaciones, [o] por descuidos de los criminales" ("El cuento" 195). Este elemento puede representar para el lector contemporáneo un principio muy elemental, como afirma Borges. Se podría pensar que los argumentos de Poe "son tan tenues que parecen transparentes. Lo son para nosotros, que ya los conocemos, pero no para los primeros lectores de ficciones policiales; no estaban educados como nosotros, no eran una invención de Poe como nosotros" (194).

Esta reflexión de Borges es esencial para la compresión de todo el género y, fundamentalmente, para entender el papel de la construcción del lector en la narrativa policial, porque es fascinante asumir que un género literario no solo se constituya como tal sino que invente un tipo de lector que hasta ese momento no existía. Si a esto le sumamos la intención de apelar a la inteligencia y el razonamiento como elementos esenciales de su constitución, la fascinación resulta doblemente atractiva. Cristina Parodi resume las leyes del género después de la aparición de los cuentos del autor de esta manera: 
Desde Poe, el esquema del policial queda, pues, formalizado. La trama se centra en un caso, presentando como un misterio -en general, un crimen- aparentemente irresoluble, pero para el que hay una solución, a la que se llega por el ejercicio de la razón. El relato debe reproducir el camino intelectual recorrido por un personaje -el detective- en sus esfuerzos por descubrir la identidad del criminal. Cumpliendo un plan rigurosamente lógico y orientado al desenlace, el policial narra la historia de la investigación, que lleva a la reconstrucción de la oculta historia del crimen. Las leyes del género imponen argumentos, funciones actanciales y reglas de composición de la trama, como la presencia de un detective razonador $-\mathrm{y}$, preferentemente, exótico-, la intervención de un colaborador algo ingenuo y de policías faltos de imaginación; la ubicación del crimen o de los potenciales culpables en un espacio limitado, que encierra las claves del enigma; la introducción de indicios falsos que conducen hacia sospechosos que deben ser pronto descartados; la verificación de datos y coartadas que obliga a cambios de perspectiva y a la formulación de hipótesis (80).

Una vez expuestas las particularidades del género, conviene reparar más detenidamente en esta idea de "construcción" del lector y de sus múltiples características aplicadas a la narrativa policial. La historiografía literaria tradicional ha destacado siempre el papel del autor en los acotados procesos de transformación social que produce un texto literario. La importancia de una obra se ve ligada en muchos casos a episodios biográficos, procesos experimentales y corrientes literarias a los que el autor pertenece. Dentro y fuera de un posible canon literario se hacía evidente que para la tradición clásica de la teoría, la influencia del escritor ante los procesos de recepción de la obra era la única existente. El papel del lector se consideraba pasivo y su actitud ante la lectura se remitía a una recepción lineal del texto. No quiero decir con esto que el autor no pensara en un público como destinatario de su obra, todo escritor narra para alguien. Pero esta condición no impide que muchas veces se olvide 
que, como sostiene Harald Weinrich, "la comunicación literaria es un juego con papeles repartidos de antemano" (199).

Parece un motivo obvio y podría decirse que el reconocimiento del pacto ha estado presente desde el origen de la literatura. En la época clásica griega, autores como Esquilo, Sófocles y Eurípides tenían en cuenta la importancia de generar conflictos emocionales que produjeran en el auditorio una experiencia catártica. En el siglo XIX, los autores se dirigían a su lector en los prólogos o notas introductorias de la novela realista, e incluso interrumpían el relato al evocar de manera expresa la presencia del lector con frases como "recordará el amable lector", etc. Pero este tipo de estrategias narrativas tenían en cuenta a un tipo específico de "consumidor literario" y no a un lector individualizado. Su incidencia en el acto recíproco de la lectura posee múltiples características y su papel no es menor, no se puede olvidar que el lector "también tiene derecho a ser tenido en cuenta. Por él hay literatura" (Weinrich 199).

La formalización del lector específico resulta importante para cualquier género, pero imprescindible para la literatura policial. Los lectores que frecuentan esta narrativa generalmente conocen sus modalidades, sus requisitos y sobre todo, sus exigencias. No es casual entonces que desde finales del siglo XIX y durante todo el siglo $\mathrm{XX}$, se haya producido esta toma de conciencia acerca de la función que cumple el lector, pues los géneros como la literatura policial dan noticia de ello. El surgimiento del policial y el lector creado por Poe indican, como afirma Weinrich, que un texto literario:

no presupone cualquier tipo de lector, y el hombre que sabe leer no leerá cualquier libro. Los autores -y naturalmente también los editores y los libros- saben muy bien esto; escriben para un determinado tipo de lector. ¿Cuáles son las conclusiones que podemos extraer de todo esto para la historiografía literaria? Por ahora, sencillamente que tiene la obligación de ocuparse no sólo del autor, sino también del lector (200).

Para Borges, este no fue un cambio menor: en "El cuento policial" afirma que quien lee una novela policial está lleno de sospe- 
chas porque "es un lector que lee con incredulidad, con suspicacias, una suspicacia especial". El autor enfatiza que el aporte fundamental del relato policial es la creación de "un tipo especial de lector" ("El cuento" 190). Gracias a esto, evidencia todas las posibilidades creativas del género contenidas en las "complejas relaciones entre escritura y lectura: el escritor crea el género; la reiteración de las convenciones genéricas refuerza las estrategias de lectura necesarias y crea a un lector" (Parodi 83-84).

Pero esta conjunción de elementos tan excepcional, no impide que la fórmula del policial pueda desgastarse, pues los requerimientos del lado de la recepción serán mayores: "un lector crecientemente más experto exige la transformación de las leyes de la narración” (84), por lo que el escritor deberá descubrir otras. Los textos policiales incluidos en Ficciones como "El jardín de senderos que se bifurcan" y "La muerte y la brújula" son una muestra clara de ese descubrimiento. Como apunta Parodi, el lector del policial sabe que su texto es tramposo y encierra un enigma:

que avanza hacia una respuesta que protege, que el escritor quiere desorientarlo y sólo entrega verdades parciales. Por eso, es un lector suspicaz, escéptico, y su estrategia de lectura se basa en la desconfianza, la duda, la incredulidad. A diferencia de la novela realista, que prefiere que olvidemos su carácter de artificio verbal, el policial no esconde ese carácter y no exige de sus lectores, como aquella, una suspensión de la incredulidad para que el universo de la ficción sea aceptado. El lector de policiales es un detective que -en el proceso de la lectura- va realizando una investigación independiente: elabora hipótesis, las modifica, las descarta, formula otras nuevas, cambia de perspectiva, sospecha el disimulo o la mentira detrás del comportamiento de los personajes, toma en cuenta la menor indicación textual como si todo dato comportara un indicio (83).

Una vez esbozadas las características del género y de sus lectores, se puede establecer la forma en que Borges subvierte ambos en 
sus relatos. Un modelo que ejemplifica con claridad la ruptura de algunos parámetros es, como ya mencioné, el cuento "La muerte y la brújula". En el prólogo a "Artificios" (1944), Borges afirma que hay dos textos en este apartado de Ficciones que merecen especial atención. Uno de ellos es este cuento perteneciente a la tradición del género policial. A pesar de contener nombres extranjeros (alemanes, escandinavos), "Ocurre en un Buenos Aires de sueños" ("Prólogo" 517) y su trama será un ejercicio constante que postula convenciones de la narrativa policial y que al mismo tiempo las subvierte.

El relato inicia con una afirmación categórica que pone en alerta al lector, Erick Lönnrot, el detective prototípico del policial de enigma, quien se compara con Auguste Dupin, no logrará impedir el cuarto crimen, pero sí preverlo, algo que contrapone la premisa del investigador que siempre consigue vencer al criminal. El detective, como señala Parodi, "se anticipará al asesino y preverá sus acciones futuras; pero también sabe que esta previsión no impedirá que el asesino lleve adelante su plan. El relato soporta esta transgresión de las leyes porque descansa en una compleja elaboración de la trama que, a pesar del anticipo, asegura que el lector difícilmente podrá dar con la solución" (85). La estrategia de identificación entre personaje y lector permite que la sexta ley del policial se cumpla, y protege a su vez otros principios y recursos dentro del texto. La rigurosa maquinaria del policial implica que "el escritor manipule esos recursos de modo que, por una parte, la narración avance linealmente hacia la identificación del culpable y, por otra, postergue el descubrimiento de la verdad, o sea que mientras orienta al lector hacia la solución, lo desvie de ella. Este requisito es inherente a un relato que está construido desde y para el final, y que no puede prescindir de la sorpresa como efecto literario" (80). ${ }^{3}$ A pesar de la elaborada configuración formal del texto, y las variantes que se introducen, Borges no prescinde del precepto básico de un final que maravilla al lector, pues la infracción de esta ley desdibujaría la esencia del cuento.

\footnotetext{
${ }^{3}$ Las cursivas son mías.
} 
Asimismo, la configuración simbólica del relato acerca de "los procesos de conocimiento y el detective como un símbolo del modo dogmático o racionalista de concebir la razón" (Castany 2), tendrá en el personaje de Lönnrot a su referente. La elección de un individuo con sus características y su identificación con el protagonista de "Los crímenes de la calle Morgue" y "La carta robada" no es casual y se adelanta desde el inicio de la historia: "Lönnrot se creía un puro razonador, un Auguste Dupin, pero algo de aventurero había en él y hasta de tahúr" ("La muerte" 535). Dupin es la representación del detective que apuesta a la razón y desde su aparición, parafraseando a Borges, los burocráticos jefes policiales han tenido infinitos espectadores, pero el especulativo personaje de Poe, unos pocos. Para el escritor argentino por cada "detective razonador -por un Ellery Queen o Padre Brown o Príncipe Salezki- hay diez descifradores de cenizas y examinadores de rastros". Y remata: "El mismo Sherlock Holmes - ¿tendré el valor y la ingratitud de decirlo?- era hombre de taladro y de microscopio, no de razonamientos" ("Jorge" 289).

No obstante la similitud, el narrador se encarga de hacer una sutil precisión: Lönnrot no es Dupin. En la formalización conceptual del segundo no caben algunas características del primero. Como en todo policial de enigma, el lenguaje es un elemento esencial para la construcción del texto. La inclusión de la conjunción adversativa "pero" sirve para introducir uno de los tantos indicios que, fiel a su naturaleza, solo podrá cobrar sentido en una relectura. ${ }^{4}$ Las dos características que suceden esta palabra -aventurero y tahúr- bastarán

\footnotetext{
${ }^{4}$ Según el diccionario de la DRAE la primera acepción de indicio implica "un fenómeno que permite conocer o inferir la existencia de otro no percibido. $L a$ fuga del sospechoso fue un indicio de su culpa" o como segunda definición: "Cantidad pequeñísima de algo, que no acaba de manifestarse como mensurable o significativa. Se hallaron en la bebida indicios de arsénico". s.v. (DRAE). Para los fines de la literatura policial y de la fantástica, el indicio es uno de los elementos más significativos de la narración, y cobra su función esencial en la relectura del texto, pues es durante este proceso que el lector se percata de su existencia y de la importancia estratégica que tiene en el relato. Entre otras funciones el indicio contribuye a la estructuración de la historia.
} 
para comprender a posteriori algunas claves del relato, pues las particularidades de la personalidad del detective conducirán su análisis por un campo "válido" para el esquema racional del personaje y del lector, pero "inválido" para los fines prácticos del verdadero conflicto.

A pesar de la exaltación de la figura analítica del detective, en "La muerte y la brújula" existe un desafío a la incuestionable conducta hipotético-deductiva. La eficacia detectivesca del personaje, en el que se resumen todas las capacidades intelectuales que tanto seducen al Borges lector, se ajusta a las convenciones impuestas por el género; pero será precisamente esa eficacia intelectual y racional la que impedirá que, tanto lector como personaje, no asuman como válidas las pesquisas más elementales de la investigación. El modelo del detective rompe su convención en este sentido, pues el razonamiento analítico no llevará a la "verdadera" solución, sino a la trampa preparada por Scharlach, el tercer y el más astuto de los detectives del cuento. Como sucede muchas veces en la realidad, la explicación más sencilla será la acertada. Mientras Lönnrot busca la respuesta de los crímenes en el conflicto religioso y la cábala judía, el criminal Scharlach -quien orquesta junto con Daniel Azevedo el primer crimen que, circunstancialmente deriva en el asesinato de Yarmolinsky- conoce a través de los periódicos los detalles de la investigación. De esta manera comienza a planear su venganza. Como afirma Parodi:

"La muerte y la brújula" complica el modelo del policial ya que el lector creado por el género se atiene a las normas, convencido de estar colaborando con el detective en la investigación de un crimen pasado, reuniendo indicios que lo conducirán a descubrir la identidad del asesino de Yarmolinsky. El inesperado desenlace le revela que, sin saberlo, también ha estado colaborando con el criminal, ayudándolo a preparar un crimen futuro, y cuya víctima será el detective (87).

La figura de Lönnrot es la del investigador quien, guiado por la razón, la erudición y el reciente conocimiento cabalístico adquirido, se excede en sus premisas intelectuales, para transformarse en un 
modelo que todo "escritor escéptico busca evitar en la realidad y castigar en la ficción” (Castany 4). El juego que implica la enorme confianza con las reglas del policial cuestiona desde el comienzo la postura de la razón como dogma. Nuevamente, Borges invierte las reglas y contradice los principios en los que más parece creer como teórico del género. Así, una de las investigaciones del cuento se desarrollará por las vías y las convenciones del policial de enigma. El lector seguirá atentamente los caminos trazados por Lönnrot, el personaje con el que obviamente desea identificarse. En realidad no se enfrenta a:

indicios referenciales dejados por el criminal, sino a indicios textuales, colocados por el escritor para ir controlando la solución del enigma. Así como el detective sigue directamente las pistas del asesino, el lector sigue las del narrador. Para descubrir las trampas que éste le va tendiendo, para descifrar sus estrategias y los artificios de composición del texto, debe identificarse con él, ser su doble (Parodi 83).

Junto con Lönnrot, despreciará todas las hipótesis de una segunda investigación, que plantea Treviranus -el clásico y aburrido jefe de policía- por considerarlas como el detective, posibles "pero no interesantes". Mientras tanto, el criminal Scharlach emprende una tercera y más eficaz pesquisa. A espaldas del astuto Lönnrot, y más aún, a espaldas del lector, se produce la más importante de las averiguaciones: lograr obtener las claves más significativas de la mente del investigador, es decir, convertirlo en el objeto de estudio para llevarlo a su muerte. Para John T. Irwin esto es posible porque Scharlach toma en cuenta el orgullo intelectual del investigador: "[Scharlach] has counted on the fact that the detective would solve the arcane clues Treviranus missed and that Lönnrot's intellectual pride would blind him, would make him think that because he was one jump ahead of the police, he was one jump ahead of the criminal as well" (30).

Al finalizar el cuento, la explicación que concluye y cierra el ciclo de la investigación/narración no la realiza Lönnrot, el detective 
con el que el lector se ha identificado, sino el criminal Scharlach, quien hasta ese momento no había tenido voz en el relato. El criminal no solo suplanta el papel del detective, sino que lo vence. El cuento concluye "no en el momento en que se revela la solución, sino en el momento en que se comete un nuevo crimen, que -contra toda ley del género- ha sido precedido por su explicación a cargo del propio asesino" (Parodi 87). Si bien Borges transgrede con el final este último precepto del género, lo reafirma en dos puntos esenciales. El primero y el más importante, es que la conclusión del cuento sigue siendo sorpresiva, incluso doblemente sorpresiva, ya que no solo el lector se desconcierta con la revelación final, sino que el propio detective es "traicionado", de alguna manera, por el autor. La segunda es que la muerte de Lönnrot -quien incluso hasta lo último, no abandona su carácter racional y especuladorcumple con la quinta ley del relato establecida por Borges: el pudor ante la muerte.

Para la escritura de "La muerte y la brújula", la fórmula extraída de los relatos de Poe es eficaz pero no suficiente. Borges, como lector de la novela policial y como un lector creado por Poe busca ir más allá, pues "escribe para un lector más escéptico" que este. $\mathrm{Al}$ mismo tiempo "que respeta las convenciones y conserva las bases sólidas de la narración, no cesa de desviar el modelo de su norma, introducir variantes, y ser un óptimo campo para las búsquedas experimentales" (Parodi 84).

Desde sus comienzos el género policial toma el modelo del detective como un símbolo inequívoco de la razón. En el cuento se produce una transgresión importante de este aspecto. "La muerte y la brújula" da una lección al lector: los caminos unívocos y las fórmulas exactas no existen en la literatura -al menos en la de Borges- y, los pactos contraídos por ambos sujetos -entendidos como emisor y receptor del texto- no siempre se cumplen. Por esa razón, no estoy de acuerdo con las conclusiones a las que llega Bernat Castany Prado sobre el conflicto del cuento aquí analizado. El crítico afirma que Lönnrot es una figura: 
especialmente atractiva para un escritor de tendencia escéptica como Borges, que convencido de que todo conocimiento es improbable, [quiere] humillar en la ficción a todos aquellos que pretendan exceder los estrechos límites de conocimiento que nos han sido impuestos. De modo que al hacer que los detectives que aparecen en su obra fracasen en sus investigaciones, lo que está haciendo Borges es reformular a la luz de su "escepticismo esencial" uno de los géneros literarios más afines a la modernidad (13).

Si bien existe una interpelación al uso acérrimo de la razón, Erick Lönnrot no es en ningún momento humillado. Su final no se sustenta en un cuestionamiento moral que implique vergüenza o deshonra. La "derrota" de Lönnrot no envuelve necesariamente una pérdida desde el punto de vista intelectual. El detective siguió un método analítico adecuado que lo condujo acertadamente al lugar al que tenía que llegar. Solo eso explica la fascinación que le produce la trama expuesta por Scharlach antes de ultimarlo. Lo único imprevisto por Lönnrot, al igual que para el lector-quien es el que recibe la verdadera lección del texto- es que la resolución del crimen no implica que pueda evitarlo.

$\mathrm{Al}$ cierre del cuento, los tres enigmas se esclarecen. Lönnrot llega al final del caso; Treviranus logra de manera hipotética y sin saberlo solucionar el suyo y, por supuesto, lo mismo sucede con Scharlach. Los tres "detectives" resuelven los tres casos y cada uno de ellos obtiene un desenlace. El primero va hacia su muerte, el segundo obtiene al final de la historia el reconocimiento del lector, pues su teoría sobre el crimen era la acertada y, el tercero, logra consumar el plan que se propuso: asesinar al hombre que capturó a su hermano y lo hirió a él terriblemente. Todo esto llega a manos del lector cuando el cuento concluye, pues en la novela policial "lo que importa es el futuro" (Parodi 83). Finalmente, como afirma Castellino: "el texto policial se presenta como un desafío a la inteligencia del lector y al ejercicio de su propia capacidad analítica. También es evidente que, esa primacía de lo intelectual que constituye el fundamento más genuino del género se aviene perfectamente con el 
temperamento de Borges, con sus inclinaciones, con sus hábitos mentales" (104).

Todo texto plantea un desafío de lectura, lo que no implica que su grado de elaboración siempre apueste a la transformación del contexto social en el que se desarrolla. A pesar de que esta condición no siempre se cumple, existe otra premisa fundamental que necesariamente debe ser atendida por el autor de una obra que se inserte dentro de parámetros tan estructurados como los de la narrativa policial: la normatividad no puede ser nunca una restricción para la constante innovación del género.

Los cuentos policiales de Borges son una prueba de ello. Tanto en la teoría como en la práctica, el escritor logró innovar varias características de un género que parecía imposible subvertir. Su profundo conocimiento del relato policial, pero más que nada, su condición de lector del mismo y sus exigencias como tal, le permitieron dar con las claves más importantes de este tipo de literatura, para hacer en definitiva lo único y más importante que se puede hacer con ella: transformarla.

\section{Obras consultadas}

Borges, Jorge Luis. "El cuento policial". Obras Completas IV. Barcelona: Emecé, 1996. Impr.

—. "Half-Way House, de Ellery Queen". Obras Completas IV. Barcelona: Emecé, 1996. Impr.

—. "Jorge Santayana". Obras Completas IV. Barcelona: Emecé, 1996. Impr.

_. "Los laberintos policiales y Chesterton". Jorge Luis Borges. Ficcionario. Una antología de sus textos. Ed., introd., pról. y notas Emir Rodríguez Monegal. México: FCE, 2003. Impr.

—. "La muerte y la brújula". Obras Completas I. Buenos Aires: Emecé, 2005. Impr.

—_. "Prólogo". Obras Completas I. Buenos Aires, Emecé, 2005. Impr. - "Sobre Chesterton". Obras Completas II. Barcelona: Emecé, 1996. Impr. 
_. "Wilkie Collins. La piedra lunar". Obras Completas IV. Barcelona: Emecé, 1996. Impr.

Castany Prado, Bernat. "Reformulación escéptica del género policial en la obra de Jorge Luis Borges". Tonos digital: Revista electrónica de estudios filológicos 11. (2006): 9. Impr.

Castellino, Marta Elena. "Borges y la narrativa policial: teoría y práctica". Revista de Literaturas Modernas 29. (1999): 89-90. Impr.

Irwin, John T. The Mystery to a Solution. Poe, Borges, and the Analytic Detective Story. Baltimore and London: The Johns Hopkins University Prees, 1994. Impr.

Parodi, Cristina. "Borges y la subversión del modelo policial". Borges: desesperaciones aparentes y consuelos secretos. Ed. Rafael Olea Franco. México: El Colegio de México, 1999. Impr.

Pastormerlo, Sergio. "Dos concepciones del género policial. Una introducción a la narrativa policial borgeana". Literatura policial en la Argentina. Waleis, Borges, Saer. Buenos Aires: Universidad de la Plata, 1997. Impr.

Ramos, Gabriel. "Razón y sueño en las Ficciones de Borges". Fervor crítico por Borges. Ed. Rafael Olea Franco. México: El Colegio de México, 2006. Impr.

Todorov, Tzvetan. "Typologie du roman policier". Poétique de la prose. Paris: Du Seuil, 1971. Impr.

Weinrich, Harald. "Para una historia literaria del lector". En busca del texto. Teoría de la recepción literaria. Ed. de Dietrich Rall. México: UNAM, 1987. Impr. 